\title{
UN ACERCAMIENTO AL ESTUDIO DE LAS INMIGRACIONES EXTRANJERAS EN EL PERÚ DURANTE EL SIGLO XIX Y LAS PRIMERAS DÉCADAS DEL SIGLO XX
}

\author{
Dr. Ernesto Maguiña Salinas \\ Profesor del Departamento de Ciencias Humanas de la \\ Universidad Nacional Agraria La Molina \\ emaguiña@lamolina.edu.pe
}

\begin{abstract}
Resumen
Las migraciones extranjeras en el siglo XIX y en las primeras décadas del siglo XX constituyeron un hecho social importante en la sociedad peruana, no obstante, su bajo volumen demográfico. El presente artículo, además de describir sucintamente la dinámica demográfica extranjera en el período indicado, explora sus principales aportes y formas de inserción económica y sociocultural, poniendo énfasis también en algunos dispositivos legales favorables a las migraciones, especialmente de europeos, para colonizar nuevas tierras. El fomento de las migraciones extranjeras, influenciado por una ideología racista, consideraba a la raza blanca como una garantía para el desarrollo del país. Paradójicamente, resultó más numerosa la inmigración asiática, especialmente de chinos, los que se insertaron como braceros, ya que los grupos de poder económico requerían peones o yanaconas, pero no colonos. Sólo una ínfima minoría de europeos colonizó tierras en la selva alta. La mayoría de inmigrantes extranjeros que llegaron al Perú para trabajar en la agricultura, en la práctica, se vincularon a actividades no agrícolas. A pesar de su escaso volumen demográfico, los extranjeros tuvieron un aporte importante al desarrollo del capitalismo en el Perú, pues destacaron en la agricultura, industria, finanzas, comercio, servicios, etc. También fue evidente su presencia en la cultura y política de nuestra sociedad.
\end{abstract}

Palabras claves: Migración, demografía, colonización, inmigrantes chinos, inmigrantes italianos, inmigrantes alemanes, inmigrantes ingleses.

\begin{abstract}
Abstrac
The foreign migrations in the XIX century and in the first decades of the XX century they constituted an important social fact in the Peruvian society, nevertheless their low demographic volume. The present article, besides describing the dynamics demographic foreigner succinctly in the suitable period, explores its main contributions and forms of economic and socio-cultural insert, also putting emphasis in some favorable legal devices to the migrations, especially of European, to colonize new lands. The development of the foreign migrations, influenced by a racist ideology, considered to the white race as a
\end{abstract}


guarantee for the development of the country. Paradoxically, it was more numerous the Asian immigration, especially of Chinese, those that were inserted since as laborers the groups of economic power peons or yanaconas, but non colonists required. A tiny minority of Europeans only colonized lands in the high forest. Most of foreign immigrants that arrived in the Peru to work in the agriculture, in the practice, they were linked to non agricultural activities. In spite of their scarce demographic volume, the foreigners, had an important contribution to the development of the capitalism in the Peru, highlighting in the agriculture, industry, finances, trade, services, etc. was Also evident its presence in the culture and politics of our society.

Key words: Migration, demography, colonization, Chinese immigrants, Italian immigrants, German immigrants, English immigrants.

\section{Introducción}

Históricamente, el Perú se ha caracterizado por su gran diversidad étnica. En el transcurso del período hispánico, confluyeron los aportes indígena nativo, español y africano, los cuales, al fusionarse biológicamente, contribuyeron a complejizar el escenario étnico, racial, social y cultural de nuestra sociedad. Desde las primeras décadas de la República se fomentó la inmigración de blancos europeos, amparada en un conjunto de leyes que favorecían su presencia. Un sector importante de la sociedad política y de la intelectualidad del siglo XIX pensaba que el aporte blanco y europeo constituía una garantía necesaria y natural para el desarrollo del país. Se propuso traerlos, pero la ejecución de la mayoría de las políticas migratorias no tuvo el éxito esperado, siendo pocos los que llegaron, sobre todo, para colonizar tierras para la agricultura.

Las migraciones extranjeras entre el siglo XIX y XX se operaron en contextos históricos marcados por periodos de inestabilidad política, así como de crisis, recuperación y bonanza económica. Todo esto contribuyó a que los alcances de los diferentes dispositivos legales, favorables para la llegada de europeos, no se ejecutaran adecuadamente. Por esos tiempos, la preocupación por atraer europeos fue compartida por casi todos los gobiernos del Perú. Sin embargo, puede afirmarse que la más importante y "exitosa" experiencia migratoria fue protagonizada por la numerosa presencia de chinos, considerada como la "verdadera inmigración", ocurrida entre 1850 y 1875 . Este hecho contó con el impulso y aliento de la influyente clase terrateniente costeńa, que necesitaba braceros y no colonos, y, de esa forma, desplazaron a un segundo plano a los europeos. En las primeras décadas del siglo $\mathrm{XX}$, destacó la presencia japonesa que, por su volumen, constituyó la segunda migración en importancia. Entre los europeos, los italianos fueron los más numerosos.

El presente trabajo tiene como objetivo principal describir, sucintamente, la dinámica y características de las migraciones extranjeras en el Perú en el siglo XIX y primeras décadas del siglo XX. El desarrollo de este trabajo trata, principalmente, del aporte demográfico de las migraciones 
foráneas, la dación de algunas leyes importantes favorables para su presencia, así como de su inserción socio-económica y cultural en la sociedad peruana. Todo esto visualizado dentro de una visión de proceso, en contextos históricos concretos que explican este hecho social.

\section{Antecedentes}

La conquista no sólo fue un hecho político, religioso, económico y cultural; sino también demográfico-social. El impacto demográfico de la conquista en América, en especial en el Perú, fue catastrófico, ya que las poblaciones nativas disminuyeron dramáticamente debido al nuevo régimen de trabajo obligatorio en las minas y los obrajes que impusieron los españoles. También fueron letales las enfermedades traídas de Europa, así como las guerras y las reducciones a la que fue confinada la masa indígena para someterla mejor.

Se afirma que el Perú ingresó al proceso de migraciones internacionales hace 500 años con la llegada de los españoles, quienes fueron además los primeros inmigrantes. Décadas después, al parecer, Garcilaso de la Vega fue el primer emigrante mestizo del Perú en Espańa, "luego lo siguieron otros mestizos en cantidades muy reducidas. Durante la colonia muchos hispanos y criollos retornarían a España. La tendencia de los que siguieron llegando al Perú fue para quedarse definitivamente" ${ }^{\text {. }}$

La predominancia de inmigrantes varones españoles contribuyó a que se unieran con las mujeres nativas, hecho que propició y aceleró el mestizaje biológico y, consecuentemente, cultural. Esta situación fue total- mente diferente a la inmigración inglesa, que involucró a familias enteras de la misma raza y religión en su desplazamiento a sus colonias de América del Norte.

La inmigración española durante el periodo hispánico no resultó muy numerosa, los que llegaron al Perú fueron autoridades políticas, otros eran generalmente grupos de campesinos. La introducción de esclavos permitió que a la población nativa y española se sumara la de procedencia negra, lo cual complejizó el mestizaje. En este período, la inmigración estuvo vetada para los extranjeros que no tenían la nacionalidad española, siendo muy pocos aquellos que lograron traspasar las barreras fronterizas. Las autoridades hispánicas ejercieron severos controles para dificultar o impedir el ingreso al territorio virreinal, especialmente tratándose de europeos no españoles.

\section{Las migraciones en las primeras décadas de la República}

Las migraciones extranjeras en este período se dieron dentro de un contexto marcado por los momentos de crisis económica y política y de inicios de la recuperación.

\section{II.1 La crisis económica y la anarquía política (1821-1840)}

Al producirse la independencia, el vínculo fundamental del Perú con el sistema económico mundial, basado en la exportación de oro y plata, estaba en crisis después de muchos años de explotación. En este periodo, el Perú no encontró un producto importante y necesario para colocarlo en los países más desarrollados. Las expor- 
taciones iniciales "se circunscribieron a metales preciosos, cortezas de quininas, materias colorantes, cueros, pieles, lanas y colocadas en sus cuatro quintas partes en Francia e Inglaterra" ${ }^{2}$. Los ingresos fiscales fueron exiguos y deficitarios. Si a esto añadimos el vacío administrativo que dejó la metrópoli española, el caudillismo militar, las luchas políticas por el control del aparato estatal, guerras civiles, la pérdida de población,* etc., se comprenderá la gran crisis que vivió el Perú como República en estas primeras décadas.

En este contexto, se incentivó la llegada de inmigrantes europeos. Los sucesivos gobiernos trataron de atraerlos, porque consideraban que eran una raza y cultura superiores, con mayores opciones para contribuir al desarrollo del país. Según Patricia Oliart, la creencia de la superioridad de la raza blanca se renueva vigorosamente, "bajo el influjo de las teorías del racismo científico europeo y del auge de las teorías darwinistas y se vuelcan en la práctica cotidiana no como una prolongación del pasado colonial, sino como parte de un aplicado esfuerzo de la élite limeña que responde a la necesidad de redefinir las diferencias sociales para implementar el nuevo ordenamiento jerárquico de la República"3.

Estas ideas, al propagarse junto con las del liberalismo, divulgaron el concepto de que existían razas superiores e inferiores. Se pensaba que "Las razas no eran inmutables, que una raza "inferior" podría mejorar si se mezclaba con otra "superior”. Según esta ideología, las sociedades latinoamericanas tenían la esperanza de transformar su destino si iniciaban un proceso de "blanqueamiento" progresivo. Para ello era necesario incrementar el contingente de la raza blanca mediante la inmigración europea" ${ }^{4}$. Según W. Stewart, "desde la independencia, los peruanos vieron favorablemente la llegada de europeos a sus costas, en especial trabajadores. Se dictaron leyes para favorecer aquella inmigración y para fomentarla se constituyeron comisiones tanto oficiales como privadas" 5 .

A partir de 1821 y a lo largo de todo el siglo XIX, los gobiernos de turno, influenciados por ideas liberales, adaptadas a las particularidades de la sociedad peruana, emitieron diferentes leyes creando el marco legal favorable para la inmigración europea, aunque estuvieron ausentes las condiciones materiales para hacerlas adecuadamente efectivas. Se dictaminó el Decreto del 17 de octubre de 1821 que concedió el libre ingreso a los extranjeros, así como otro del 19 de abril de 1822 que autorizaba que todo extranjero que tuviera "alguna ciencia y arte" podía ingresar al país. En ambos casos también se garantizaba el desarrollo de sus actividades económicas.

Sin embargo, existió un numeroso grupo de personas, sobre todo, de origen americano y español, que viviendo en el Perú desde antes de la independencia, después de 1825 se convirtieron en extranjeros como consecuencia de una conciencia nacional en torno a nuevos intereses o delimitaciones políticas o administrativas. En las primeras décadas de la República, estas personas no fueron una población inmigrante en sentido estricto sino una población legalmente extranjerizada. 
La Constitución vitalicia de 1826 consideró peruanos a los extranjeros "que obtuvieran carta de naturaleza o contasen con tres ańos de vecindad en el territorio de la República, también señaló como ciudadanos a los extranjeros casados con peruanas que supieran leer y escribir y tuvieren empleo o industria o profesaran una ciencia u arte..."'

La Ley del 21 de noviembre de 1832, que creaba el Departamento de Loreto, fue el primer dispositivo legal para facilitar el ingreso de inmigrantes al Perú. En su artículo $7^{\circ}$ decía: "A cada uno de los extranjeros que se avencindasen en las nuevas reducciones se les asignarán por el subprefecto de la provincia las tierras que puedan labrar y gozarán de los privilegios y exoneraciones que conceden las leyes a los poseedores de tierras eriazas"

Al respecto, Juan de Arona, dijo que "la ley en referencia fue de demarcación política y con el doctor Ulloa, podemos considerarla como el primer paso aunque tímido dado por el gobierno independiente del Perú a favor de la colonización de la montańa”". Sin embargo, por esos ańos fueron pocos los inmigrantes que llegaron a la selva. Otro dispositivo que expresaba el intento de atraer migrantes fue el Decreto del 14 de Marzo de 1835, emitido por el General Felipe Santiago Salaverry. Uno de sus párrafos decía: "Todo individuo de cualquier parte del globo es ciudadano del Perú, desde el momento en que pisando su territorio quiera inscribirse en el Registro cívico". Se excluía a los que "no tenían industria". Pero al poco tiempo el mismo General tuvo que anular dicha declaración por la oposición que encontró, en especial dentro de los sectores más conservadores.

PEn ese tiempo, se formaron grupos de extranjeros o colonias de súbditos de otros países, especialmente europeos. Aunque poco numerosos, fueron alcanzando importancia, sobre todo en la vida económica del país. En la década de 1830, por ejemplo, los ingleses y norteamericanos se dedicaban a las finanzas y al gran comercio, los franceses destacaban como comerciantes en joyas, vendedores de artículos femeninos, sastres y peluqueros. Los italianos y los españoles constituían las colonias extranjeras con mayor población. Los españoles todavía mantenían su prestigio, y se adaptaban con más seguridad, porque los familiares, amigos o conocidos que residían en el Perú facilitaron su incorporación a nuestra sociedad. Hay que señalar que la mayoría de los que ingresaron al país lo hicieron por su cuenta, al margen de la legislación migratoria.

En 1840 se realizó un censo de extranjeros, el cual estableció una cifra de 1,025 en las provincias (excluyendo Lima y haciendas). Aunque las cifras contenían serias omisiones, presentaban algunas características importantes. Por ejemplo, esta población se localizaba mayormente en La Libertad, Callao y Junín, es decir en zonas productivas muy importantes. $37 \%$ eran españoles, que en muchos casos residían en el Perú desde hacia bastante tiempo; $38 \%$ estaba formado por ecuatorianos, chilenos, bolivianos, argentinos y colombianos, preferentemente asentados en las zonas de fronteras cercanas a sus países; y menos del $20 \%$ de extranjeros correspondían a europeos de otras naciones ${ }^{9}$. 


\section{2 Inicios de la recuperación econó- mica}

En la década de 1840 , se inició un periodo de recuperación y bonanza económica sin precedentes, sustentada en las mayores exportaciones y ganancias proveniente de la venta del guano, que reinsertaron al Perú en el sistema económico mundial. Así, en 1841 el primer envío de este fertilizante representó el 30\% de todas las exportaciones peruanas; en 1850 alcanzó el 50\%. En 1849, el 88\% del guano importado por Gran Bretaña provenía del Perú. Esta nueva situación fue favorable para seguir fomentando las migraciones foráneas, por lo cual se emitieron más leyes de inmigración.

El 25 de enero de 1845 mediante otro decreto, se ofreció a los inmigrantes europeos tierras y otros privilegios para colonizar Pozuzo, previa construcción de un camino desde Pasco y el mejoramiento de otro desde Mairo. "A cada uno de los extranjeros que se avencidasen en las nuevas reducciones de conformidad con la ley del 21 de noviembre de 1832 , se les asignarán tierras en propiedad para que puedan labrar y gozarán de los privilegios que corresponden a los nuevos pobladores"10. Juan de Arona afirmaba que esta ley "tampoco puede considerarse como protectores de inmigración, sino como otro atisbo de colonización". No existe información sobre el número de personas que llegaron alentados por estas promesas. El 17 de noviembre de 1849, según Juan de Arona, se emitió la "verdadera y primera ley de inmigración”.

El discurso de los gobernantes incentivando la inmigración extranjera era alenta- do también por europeos radicados en el Perú. Ellos fomentaban la migración del viejo continente con el objetivo de propagar un espíritu liberal más abierto en nuestra sociedad. Consideraban que bajo la influencia directa de esas ideas los abusos del ejército, de los magistrados y del clero desaparecerían, amén que sería ventajoso contar con una población laboriosa e inteligente. Estaban convencidos de que la fusión de las razas era una condición previa para la prosperidad del Perú y solo la inmigración europea podía facilitar y activar esa fusión ${ }^{11}$. Según Patricia Oliart, algunos intelectuales locales, coincidentemente, pensaban que "la presencia de los gringos macizos era deseada, entonces, para que ellos hicieran lo que aparentemente los peruanos no podían hacer por ellos mismos: Mejorar la raza, modernizar el país y desarrollar la democracia y la industria" ${ }^{12}$.

En 1850, en el país vivían aproximadamente 45,000 extranjeros (el 2.3\% de la población nacional), muchos de los cuales radicaban desde hacía muchos años. Los verdaderos inmigrantes, especialmente europeos, en su mayoría fueron ajenos a una política de colonización de tierras. La población del Perú, en ese mismo año, superaba los dos millones de habitantes y era predominantemente indígena.

En la década de 1840, Lima experimentó un rápido proceso de recuperación y expansión demográfica. Esta ciudad, entre 1839 y 1857, aumentó de 55,600 a 94,000 habitantes. Von Tschudi estimaba que en 1842 en Lima vivían 53,000 personas, de los cuales $40 \%$ eran extranjeros mulatos y mestizos, $32 \%$ criollos blancos, 
$19 \%$ negros y $9 \%$ indios $^{13}$. Los extranjeros, si bien fueron pocos a nivel nacional, se concentraron en esta ciudad; en este grupo predominaron los europeos.

En esta década, las actividades económicas vinculadas al pequeño y mediano comercio ocupaban en su mayoría a mestizos, indios y en menor medida a los extranjeros. Las pocas actividades relacionadas con las finanzas y el gran comercio estaban controladas por europeos, principalmente ingleses. El auge económico incrementó la presencia de extranjeros insertos en las "sucursales de empresas que operaban en la capital y personal de las casas matrices europeas. La mayor parte eran de origen inglés y francés y, en menor medida, italianas, alemanas y norteamericanas" ${ }^{14}$.

\section{Las migraciones en la segunda mitad del siglo XIX}

\section{III.1 De la bonanza a la crisis económi- ca (1850-1879)}

Después de la década de 1840, la demanda del guano siguió ascendiendo. En 1854, el $93 \%$ de las exportaciones que realizó el Perú correspondió a este fertilizante. En 1870, el guano representó el 81.5\%, en cifras absolutas enviaron al extranjero 698,176 TM, la mayor cantidad de abono de toda su historia. Pero, en 1875, la exportación de este recurso llegó a su punto más bajo (38\%), destacando más bien el envió de salitre con el 51.5\%. A mediados de la década de 1870 , se hizo más evidente el deterioro y crisis de la economía guanera. La recaudación fiscal apenas alcanzaba para pagar la deuda externa, los gastos ordinarios gubernamentales eran deficita- rios. En 1876, se suspendió el pago de la deuda externa; el gobierno estaba en bancarrota.

La agricultura de la costa recibió parte de los beneficios provenientes de la venta del guano. Hasta la primera mitad del siglo XIX, esta actividad se encontraba postrada y en situación de crisis, debido, entre otras causas, a la escasez de mano de obra, ya que gran parte de la población afrodescendiente se había librado de la esclavitud. La libertad parcial decretada por el general San Martín beneficiaba a los afrodescendiente nacidos a partir del año 1821, muchos de los cuales rompieron sus vínculos con la tierra y optaron por la emigración. El 5 de diciembre de 1854 un decreto firmado por Ramón Castilla los declaró completamente libres, beneficio que alcanzó a cerca de 26,000 esclavos. Unos meses antes, el 5 de julio de 1854, Castilla había abolido el tributo del indio.

La manumisión definitiva de los esclavos fue indemnizada con dinero proveniente de las ganancias del guano, lo cual puso a disposición de los propietarios importantes capitales, que en varios casos fueron utilizados para financiar el desarrollo de la agricultura costeńa. Pero, por otro lado, significó la paralización de su producción ante el masivo abandono de las haciendas por parte de los negros. Estos capitales transferidos hacia la agricultura resultaron más importantes cuando en la década de 1860 comenzó a crecer la demanda de azúcar y algodón en el mercado mundial.

La afluencia de extranjeros a nuestro territorio se operó en este contexto. A partir de 1850 , se inauguró una nueva etapa carac- 
terizada por el mayor énfasis que puso el Estado peruano en atraer migrantes para resolver el problema de escasez de mano de obra para la agricultura, extracción del guano y construcción de ferrocarriles. Pero también tenía como objetivo buscar la modernización de la agricultura y, en general, contribuir al desarrollo del país. Las políticas referidas a las migraciones extranjeras trataron de ser más coherentes, buscando estar de acuerdo con los cambios que se venían operando en la estructura productiva en relación a las exportaciones.

El 17 de noviembre de 1849, cuando el Congreso peruano aprobó la Ley General de Emigración, no había sido abolida definitivamente la esclavitud, tampoco se había extinguido el tributo indígena*. El interés por obtener mano de obra extranjera expresaba que Castilla buscaba crear condiciones favorables para la futura liberación de los afrodescendientes. Desde la segunda mitad del siglo XIX hasta antes de la Guerra del Pacífico, hubo una mayor presencia migratoria internacional como resultado de convenios entre gobiernos. Sin embargo, el volumen de inmigrantes extranjeros: orientales, europeos y americanos no produjo cambios mayores en la velocidad del crecimiento demográfico del Perú.

\section{III.1.1 La migración china y europea}

Abordaremos, brevemente, aspectos importantes de las principales minorías étnicas que llegaron al Perú entre 1850 y 1875.

\subsubsection{Los chinos}

El 17 de noviembre de 1849, el Congreso peruano aprobó una Ley General de Emigración debido a la falta de mano de obra, mediante la cual, según Basadre, se ofreció "una prima de treinta pesos a todo introductor de colonos extranjeros de cualquier sexo, cuyo número no bajara de 50 y cuyas edades fuesen de 10 a 48 años $^{15}$. Bajo la influencia de Domingo Elías, importante capitalista y terrateniente, se promulgó la Ley que tenía como objeto, según W. Stewart "favorecer la entrada de chinos. Paz Soldán, acérrimo opositor, la apodó la ley china y así se le conoce popularmente. Con algunas modificaciones es el origen del movimiento migratorio de chinos en el Perú" ${ }^{16}$. Esta Ley pretendía introducir inmigrantes europeos, pero en la práctica la mayoría de los que ingresaron al país fueron trabajadores asiáticos en calidad de contratados.

Desde febrero de 1850 hasta julio de 1853, llegaron al Perú "3,932 colonos, de ellos 2,516 fueron chinos, 320 irlandeses y 1,096 alemanes, cuyas primas de acuerdo a la Ley de 1849 ascendieron a 117,796 pesos. La Resolución Suprema del 5 de mayo de 1852 señaló que de los 50,000 pesos votados para la inmigración 25,000 se debían dedicar a la de origen europeo"17. Esta Resolución fue emitida al gobierno de Echenique, el mismo que trató de acelerar la inmigración europea.

Muchos chinos en su país de origen, fueron engañados y enviados incluso con violencia y crueldad al Perú, muchos viajaron en las peores condiciones, a bordo de barcos sobrecargados apodados "infiernos flotantes" que recorrían 9,000 millas en 120 días desde Macao hasta el Callao. En ese largo viaje muchos murieron. Una vez en 
tierra firme, las condiciones de vida de los culí en sus lugares de trabajo fueron semejantes o peores al estado de servidumbre y explotación en que se mantuvo a la población indígena y afrodescendiente ${ }^{18}$. Como su contrato era de "solo ocho años", se les explotaba al máximo, al extremo que muchos murieron antes de culminar su tiempo de contrato o se buscaban mecanismos para prolongarlo. Se dieron decretos para mejorar la condición de los culíes chinos, como los promulgados el 3 de marzo de 1853 y el 9 de julio de 1854, pero fueron ignorados por los hacendados. Hasta que, finalmente, por Decreto Ley del 6 de marzo de 1856, el gobierno del Presidente Ramón Castilla suprimió el arribo de "colonos chinos".

Pero esto no anuló el tráfico de chinos, los cuales siguieron llegando, aunque en menor cantidad. La presión de los hacendados, urgidos de mayor número de mano de obra, debido al incremento de la demanda mundial de algodón, hizo que el Congreso aprobara una nueva "Ley china" el 15 de enero de 1861, pero el gobierno de Castilla la observó. Sin embargo, el Congreso promulgó la Ley el 14 de marzo del año 1861. Los inmigrantes chinos siguieron desembarcando en el Perú hasta la primera mitad de la década de 1870 .

J. Levin estima que "Entre 1849 y 1875 llegaron unos 90,000 culies* al país y 10,000 perecieron a bordo de las naves que los traían como esclavos. De estos 90,000 culies varios miles trabajaron en las islas guaneras, entre 5,000 y 10,000 se emplearon en la construcción de ferrocarriles y cerca de 80,000 sirvieron en las plantaciones costeras de algodón y azúcar" ${ }^{19}$. En los viajes el número de muertos fue alarmante, así en 1860 de 2,000 embarcados en el puerto de Macao, fallecieron en el camino el $30 \%$. Pero en 1863 , la situación fue peor, ya que de 1,726 inmigrantes, murieron en la travesía el 42\%. En el año 1872, fue aún más trágica, arribó la mayor cantidad de chinos $(14,505)$ y perdieron la vida en el viaje más de 1,100. (Ver cuadro 1).

César Ugarte señaló que la migración china, guiada "por un propósito mercantil se hizo en condiciones desastrosas, sin examen alguno de sus costumbres, moralidad y aptitud física... El acentuado avance de la industrialización agrícola y de la agricultura del siglo pasado se debió a la formidable contribución humana que vino desde el puerto de Macao"20. Por su parte Watt Stewart dice que "sin el humilde culí, la agricultura hubiera languidecido, los ricos depósitos de guano se hubieran quedado sin explotar, la industria y la construcción de ferrocarriles se hubieran estancado. A pesar de su debilidad física y de los vicios que trajo consigo o los que le achacaron, el culí rindió con su labor un gran servicio al país"21.

Como resultado de los maltratos de los hacendados y enganchadores, los inmigrantes chinos comenzaron a disminuir rápidamente. Esteves afirma que "No han transcurrido 25 ańos cuando ya casi no puede contar con ellos la agricultura, por la muerte prematura de un gran número, por la terminación de muchos de sus contratos, ya por la evasión de haciendas a las colonias que de ellos existen en Lima" ${ }^{22}$. Los chinos que concluían sus contratos se recontrataban nuevamente, pero como trabajadores libres, algunos 
incluso lo hicieron como enganchadores. Otros se desplazaron o residieron en diferentes pueblos costeńos o en ciudades donde instalaron pequeños negocios. Estas tendencias se acentuaron en la década de 1880 cuando llegó un nuevo grupo de inmigrantes chinos, procedentes de Estados Unidos y Hong Kong. Aunque poco numeroso, traían capitales para invertir en diversos negocios.

\subsubsection{Los europeos}

La inmigración europea fue menos numerosa que la china, siendo aún más reducida aquella relacionada con la colonización de tierras. A pesar de los intentos del Estado peruano (amparado en diferentes decretos, leyes y autorizaciones), las políticas de colonizaciones fueron escasamente exitosas en la segunda mitad del siglo XIX. Además de la Ley de Inmigración de 1849, ejecutada en 1850, existió el Decreto Supremo del 4 de junio de 1853 donde se aprobó la inmigración de alemanes y austriacos. El gobierno de Rufino Echenique emitió la Resolución Suprema del 6 de diciembre de 1855 que se dejó sin efecto la Resolución anterior.

En el transcurso del segundo gobierno de Castilla, se dieron otras leyes como la Resolución Suprema del 6 de diciembre de 1859 para traer 25,000 irlandeses, la Resolución Suprema del 22 de noviembre de 1859 para que vengan 10,000 españoles y la Resolución Suprema del 31 de diciembre de 1860 para la inmigración de 20,000 colonos. Durante el gobierno de Mariano Ignacio Prado, se emitió la Resolución del 25 de junio de 1857 que aprobó el contrato para que lleguen 5,000 alemanes.
El intento más serio de organización para atraer europeos al Perú ocurrió durante el gobierno de Manuel Pardo. El 14 de agosto de 1872, se creó una "Comisión Consultiva de Inmigración" y el 17 de diciembre del mismo año por Decreto Supremo nació la "Sociedad de Inmigración Europea" para promover y facilitar la venida de colonos selectos de esa procedencia, ocuparse de los cuidados que debían recibir, velar por la colocación de ellos y darles elementos de trabajo ${ }^{23}$.

El 28 de abril de 1873, se expidió una nueva Ley que ratificó la importancia de la inmigración para el "adelanto de los pueblos". Se autorizaba al gobierno central a invertir 100,000 soles en el fomento de la colonización europea y otorgaba incluso terrenos irrigados de la costa de propiedad del Estado. Los colonos estaban obligados a reembolsar al erario nacional los gastos ocasionados a excepción del transporte. Esta Ley buscaba una verdadera colonización, así entre 1873 y 1875, llegaron al Perú 3,000 colonos, aunque en la práctica no ocuparon tierras en la costa. Sólo un grupo reducido se movilizó a la selva central.

El asesinato de Manuel Pardo, además de la crisis política y económica frustraron los intentos de atraer más inmigrantes europeos. Brevemente, abordaremos algunos casos de migraciones europeas, asociadas a proyectos de colonización.

\section{a. Irlandeses}

Paralela a la inmigración china se realizaron esfuerzos para atraer europeos. De 
esta manera, en 1851, llegaron 350 irlandeses, los cuales sin embargo no pudieron encontrar trabajo. Además el gobierno de aquel entonces no les proporcionó ayuda, a pesar de las promesas y contratos que existieron. Como resultado muchos irlandeses se vieron obligados a mendigar en las calles de Lima, retornando algunos a su lugar de origen.

W. Stewart hace referencia a un doctor de apellido Gallager, que afirmaba haber traído de Europa a varias familias irlandesas para trabajar en su fundo del Callao, "pero pensaba que era aconsejable emplear chinos: El infraescrito había despedido a sus colonos europeos porque era imposible satisfacerlos a pesar que se les daba el doble de la comida consumida por asiáticos y trabajadores nativos" 24 . El 27 de agosto de 1859, durante el gobierno de Castilla, se aprobó un contrato para capatar 25,000 irlandeses, pero esta meta no se llegó a concretar por la decidida oposición del gobierno de Inglaterra.

\section{b. Españoles}

Los esfuerzos del Estado peruano por atraer migrantes europeos prosiguieron, así, en 1859, se establecieron concesiones y facilidades "para asentar 10,000 españoles entre 16 y 40 años de edad aptos para la labranza. A los concesionarios se les prometió 30 pesos por individuo y el migrante estaba obligado a trabajar como jornalero durante cinco años en las haciendas de la costa"25.

A pesar de la decidida oposición del gobierno español, se logró contratar un grupo reducido de 58 familias vascongadas para trabajar en la hacienda "Talambo", localizada en el valle de Jequetepeque. Su propietario, Manuel Salcedo, había ampliado su frontera agrícola, irrigando nuevos terrenos para cultivar y exportar algodón en gran escala para satisfacer su creciente demanda mundial. Estas familias para llegar al Perú tuvieron que zarparon por el puerto francés de Burdeos y arribaron al Callao el 19 de julio de 1860 . Manuel Pardo, en un artículo publicado en la "Revista", saludó el inicio de la inmigración vascongada, realizada en función de los intereses del país.

Jorge Basadre, al respecto, decía: "La contrata tenía como plazo de duración 8 años desde el momento del arribo a la colonia. En los dos primeros, los inmigrantes deberían ser mantenidos y alimentados y auxiliados con animales y aperos de labranza, correspondiendo además un salario mensual de un peso de plata a los menores de 12 años y de dos a los que pasaran de esa edad. Calculaba Azcarate, que a partir del tercer ańo, cada familia poseería 166.5 quintales de algodón por cosecha fuera de los granos y hortalizas y de los pastos que cultivarían enteramente para ellos" 26 .

En el transcurso de tres años, se modificó el objetivo inicial de la inmigración, si bien algunos colonos habían logrado acumular pequeñas fortunas, otros habían descuidado la producción de algodón para dedicarse a cultivos de pan llevar. "Varios se habían instalado en la zona fronteriza de la hacienda, en áreas de propiedad precaria en donde habían ganado buenos terrenos de cultivo y construido casas, lo que creaba una especie de amenaza interna al equilibrio de la hacienda" ${ }^{27}$. Según Ma- 
nuel Burga esta fue la causa fundamental por la que fracasó la inmigración vasca. Se desataron conflictos y rivalidades entre colonos y nativos, también entre los mismos colonos con el propietario de la hacienda. En 1863, ocurrió finalmente un incidente sangriento, donde murieron varios espańoles. Los sobrevivientes regresaron a su país, dando por concluido este proyecto de colonización.

Este inesperado desenlace fue transformado en un incidente internacional por parte del gobierno de España. Pero en realidad era el pretexto que buscaba este país para sus reivindicaciones coloniales, produciéndose un grave conflicto bélico con el Perú en mayo de 1866.

El fracaso de esta inmigración paralizó los intentos de una agricultura capitalista comercial, pero sin desarrollo equivalente de sus fuerzas productivas, sin mecanización, sostenida sólo en la entrega de tierras en condición de parceleros para recibir una renta agraria igual a la mitad de las cosechas recibidas. Según Manuel Burga, se intentó la yanaconización de la población europea inmigrante, ya que el hacendado buscaba la rentablidad más que la productividad y modernización de sus tierras.

\section{c. Alemanes}

Al amparo de la Ley de 1849, en los primeros años de la década de 1850 arribaron al Perú 1,096 alemanes. Trabajaron en diferentes actividades, algunos lo hicieron como domésticos y artesanos en Lima. Según Ugarte, en 1853, con la mayoría de alemanes se intentó iniciar la colonización de Loreto, pero los resultados fueron de- sastrosos, pues sólo unos pocos llegaron a Moyobamba, capital en ese momento del departamento. Otros regresaron a su país, ya que reducidos a la más completa miseria deambulaban por las calles de Lima implorando caridad. Según Basadre, la colonización de Tarapoto y Moyobamba implicó un gran gastó, que no fue acompañado de adecuadas medidas de seguridad, necesarias para facilitar el viaje a pesar de que se trataba de zonas distantes y entonces aisladas del resto de la República ${ }^{28}$.

El 4 de junio de 1853, se celebró un contrato entre el Varón Damián Von Schutz (empresario y explorador alemán) con el gobierno peruano mediante el cual, en el transcurso de 6 años, debían venir 13,000 alemanes para desplazarse por el Amazonas y colonizar algunas tierras de la selva baja. Según Juan de Arona se "les concedía además dieciseis fanegadas de terreno por cada emigrado que introdujeran. Los inmigrados por el hecho de admitir los terrenos del Estado y gozar de su protección quedaban de ciudadanos peruanos. Si cumplido los seis años no hubieran introducido los trece mil colonos, terminaba la concesión y solo tendrían derecho a las primas correspondientes por los colonos introducidos" 29 . Sin embargo, este contrato caducó, sin su ejecución, en diciembre de 1854 .

El 6 diciembre de 1855 se emitió un Decreto Supremo donde se renovó el contrato con Schutz, y se insistió en colonizar la selva, la cual "debía empezar por la parte más civilizada y no por el litoral de Amazonas, y se disponía que el número de colonos, diez mil por lo menos en 10 ańos, pasaría a establecer la colonia donde 
el gobierno determinara. La primera colonia compuesta por 500 individuos de todo sexo y edad, debería llegar en todo el año de 1856 y pasar a Pozuzo u otros puntos que el gobierno señalara" ${ }^{30}$. El gobierno se encargaría del transporte hasta el Callao, facilitaría el desplazamiento de los colonos $\mathrm{y}$, durante tres meses, suministraría víveres, semillas y útiles que los colonos devolverían después de cinco años. Además, cada individuo mayor de quince años recibiría una gratificación de treinta pesos sin obligación de devolución. Por Resolución del 21 de enero de 1857, el gobierno inició la construcción de un camino de Cerro de Pasco a Pozuzo, pero quedó inconcluso.

El 19 de marzo de 1857, doscientos austriacos (tiroleses) salieron del puerto de Amberes rumbo al Callao. En el Perú se les unieron 100 alemanes remanentes de la inmigración anterior. Después iniciaron su travesía hasta la selva alta, pasando las alturas de Cerro de Pasco. Los alimentos se agotaron en pocas semanas, el camino inconcluso de Pasco a Pozuzo alargó el viaje y las penurias. Dos años después, en julio de 1859 sólo 170 personas (entre hombres y mujeres) llegaron a la "tierra prometida", fundando la colonia de Pozuzo entre los ríos Pozuzo y Huancabamba.

Los expedicionarios ocuparon una zona boscosa que después deforestaron, de esta forma obtuvieron excelentes tierras para la agricultura. El Estado los apoyó durante tres años con una subvención de mil pesos mensuales, hasta que en 1860 dejó de hacerlo creyendo que habían prosperado. Los colonos cultivaban tabaco, café, arroz, caña de azúcar, algodón, coca y yuca. También disponían de una variedad de anima- les domésticos. Algunos de sus productos lograban sacarlos por caminos difíciles de herradura.

Con el propósito de desarrollar esta colonia, en 1867 y 1870 los gobiernos de Mariano I. Prado y José Balta, respectivamente, estipularon dos nuevos contratos. En el primero se pactaba que debían venir al Perú 5,000 alemanes, pero sólo arribaron 321 en el año 1868, los cuales se desplazaron a Pozuzo. En 1891 ocho colonos salieron de Pozuzo para buscar nuevas tierras, después de recorrer 80 kilómetros llegaron ese mismo año a Oxapampa. Otro grupo arribó a Chontabamba, donde encontraron condiciones favorables para la producción agropecuaria, quedándose definitivamente.

Según Giovanni Bonfiglio, el segundo contrato no llegó a ejecutarse, pero se concedió 10,000 soles de subvención a 30 familias, que debían desplazarse a la colonia por el río Amazonas hasta el puerto de Iquitos.

\section{d. Italianos}

Hubo algunos italianos en el interior del país, vinculados a diferentes actividades económicas. Alrededor de 1860, un grupo se internó en la región de Chanchamayo, pero al poco tiempo abandonaron dicho lugar debido a su aislamiento. Durante el gobierno de Manuel Pardo, funcionó la Sociedad de Inmigración Europea (1873-75) que patrocinó la llegada de aproximadamente 3,000 europeos, predominantemente italianos, también arribaron algunos franceses y suizos. Este grupo se dirigió mayoritariamente a colonizar Chanchamayo. 
Inicialmente, se tenía previsto colonizar tierras en la costa, pero no fue posible debido a la dificultad del gobierno para irrigar nuevas áreas y a la negativa de los hacendados costeños a contratar inmigrantes europeos. Por ejemplo, Jorge Basadre se refiere como un experimento fallido la presencia de una pequeña expedición de napolitanos contratados por Tomás Caivano para trabajar en una hacienda de $\mathrm{Ica}^{31}$. La mayoría de italianos encontró empleo en Lima, en negocios o empresas de compatriotas y desnaturalizaron así el objetivo de esta inmigración.

A través de la Sociedad de Inmigración Europea, se intentó dinamizar la colonización europea, ya no a la costa sino a la selva, pero buscando al inmigrante italiano "porque era el que más se asemejaba al elemento nacional". Con la ejecución del proyecto de colonización de Chanchamayo se otorgaron extensos terrenos. Adicionalmente, el gobierno se comprometió a anticipar utensilios, víveres y dinero mientras se terminara con la construcción del ferrocarril de Lima a La Oroya. Este tramo de ferrocarril reduciría a 160 kilómetros al lomo de bestia el camino desde la última estación hasta el lugar donde se encontraba la colonia ${ }^{32}$.

El gobierno incumplió sus promesas, después el presidente Pardo fue asesinado, y con ello disminuyó el apoyo oficial. La sociedad colonizadora terminó por disolverse, desalentó a grupos de colonos que fueron emigrando a otros lugares del país. Pero este asentamiento, al margen del apoyo oficial, comenzó a prosperar después de la Guerra del Pacífico, debido al alza de los precios internacionales del café y a la posibilidad de unirse con otros colonos. Hubo un momento en que sus tierras llegaron albergar hasta 2,000 habitantes, la mayoría italianos, considerados los más exitosos. La crisis de esta colonia se inició con la disminución del precio del café y con el alto costo de los fletes. Además, algunas casas comerciales de Lima mantuvieron precios onerosos a los artículos que los colonos consumían, contribuyendo a la ruina de muchos.

En 1892, llegó un grupo de 100 italianos para colonizar tierras en la selva, en la región del Perené, acogiéndose a un convenio entre la Peruvian Corporation y el gobierno peruano. Con el tiempo estos colonos fueron abandonados a su suerte, así quedaron apenas seis italianos después de cinco años.

A pesar de los fracasos y gestiones poco fructíferas, la población italiana en el Perú siguió creciendo algunos años más. A comienzos del siglo XX esta colonia fue calificada como "la piu numerosa e la piu prospera” por los progresos alcanzados.

\section{e. Ingleses}

Los ingleses llegaron al Perú como producto de la expansión comercial británica desde el inicio del período republicano, no tanto como parte de un flujo migratorio o proyectos de colonización. Más que inmigrantes eran empleados de compañías inglesas ligadas a actividades portuarias, mercantiles y financieras. Este grupo europeo tuvo importante presencia en la vida del Callao con la empresa Pacific Steam Navigation Company, la construcción del muelle Darsena, el ferrocarril Lima-Callao 
y las numerosas empresas industriales existentes en aquella época como la Casa Gra$\mathrm{ce}^{33}$. En el año 1859, residían en el Perú 1,397 ingleses, incrementándose en 1876 a 3,379. Según Juan de Arona, "en 1876, habían 1,296 ingleses en el Callao, 507 en Lambayeque, 491 en Tarapacá y sólo 475 en Lima”. A comienzos del siglo XX, declinó la influencia económica de Inglaterra en el Perú, disminuyó también el número de ingleses, más rápidamente comparada con otros grupos europeos. Por esos ańos, la población inglesa se redujo a 442 personas.

\section{III.2 La postración e inicios de la recu- peración económica (1880-1899)}

Económicamente, la guerra con Chile significó la pérdida del salitre, una inmensa deuda externa y la ruina de la agricultura costeña. El guano fue dejando de ser necesario en el mercado mundial, debido al descubrimiento de fertilizantes sintéticos. $\mathrm{Al}$ quedarse sin sus principales fuentes de financiamiento, la situación en el Perú se agravó. Sin embargo, según Bardella, "no transcurrió mucho tiempo cuando la producción de cueros vino a reemplazar con creces al guano y al salitre en la demanda internacional, sobre todo, en $1888^{34}$. En la última década del siglo XIX, se observó una mejor situación económica, administrativa y hacendaria en el país, debido a la reactivación de la agricultura, con mayores exportaciones de azúcar, en menor medida de algodón y de lanas, carbón vegetal y minerales.

En la década de 1880, la guerra y sus catastróficas consecuencias disminuyó la inmigración extranjeras, en especial eu- ropeos. En la década de 1890, intentó avivarse a través de varias leyes. Incluso antes, el 29 de octubre de 1888, el gobierno de Andrés A. Cáceres emitió una Resolución Suprema en relación a una solicitud de tierras en la selva. Un párrafo decía "que la adjudicación de los terrenos es a título onerosa, compensándose el valor de ellos con los beneficios que deriva el estado de la colonización con familias europeas, que los peticionarios quedan obligados a introducir y establecer en esos terrenos a su costa y sin gravamen del fisco" ${ }^{35}$. El mismo gobierno, el 23 de noviembre de 1889, estableció un Convenio con los tenedores de bonos de la deuda externa donde autorizaba la prolongación del ferrocarril de La Oroya hasta un punto fluvial. El Estado peruano cedía 5,000 hectáreas por cada kilómetro de línea férrea construida, concediendo facilidades a los colonos que quisieran habitar esas zonas.

El gobierno de Morales Bermúdez emitió el 11 de noviembre de 1890 una Ley donde se disponía el traslado de colonos alemanes al Perú. El 14 de octubre de 1893, se promulgó otra Ley de inmigración y colonización, ratificando el interés de atraer europeos, donde además se reafirmó el principio de que el Estado protegía y fomentaba la inmigración. Basadre dice que se definió "como inmigrantes a los extranjeros de raza blanca que llegaran a la República para establecer en ella y a los colonos especialmente contratados. Tenían derechos que incluían pasajes, terrenos gratis y exoneración de impuestos" 36 . Algunos extranjeros la aprovecharon en el período del boom del caucho. Pero esta Ley fue derogada el 21 de diciembre de 
1898 por el gobierno de Nicolás de Piérola debido a que no se logró la inmigración ni la colonización esperada.

Un nuevo proyecto para atraer migrantes italianos quedó sin efecto en 1897 durante el gobierno de Nicolás de Piérola, debido a que las autoridades y la prensa italiana lo consideraron "desastroso y denigrante". En 1898, fue acogida una propuesta para que lleguen más italianos como colonos. Pero el desprestigio de la política inmigratoria peruana hizo fracasar este intento. Un italiano apellidado Salini propuso traer 300 familias, compatriotas suyos, a la región del Pachitea, a quienes debía adjudicarles tierras (que serían propias después de 5 años), transporte, alimentación gratuita durante un año, atención médica, herramientas, semillas, animales de trabajo y reproducción, etc. Exigía, además, autonomía municipal, siendo rechazado por el gobierno peruano.

Juan de Arona afirmó que la inmigración oficial en el Perú durante 26 años se redujo "a unos tres mil del año 50 al 53, otros tanto del 72 al 76 y 600 colonos alemanes para el Pozuzo traídos en dos partidas de a 300 en los ańos 57 y 68"37. Lapidariamente resumió la inmigración europea del siglo XIX en una sola palabra: fracaso.

\section{III.3 Algunos aspectos socio-económicos}

\subsection{Chinos}

Con relación a los chinos, como ya se mencionó, una parte de esta comunidad al terminar sus contratos se quedó en el campo, pero otra se desplazó a las ciudades, instalando pequeños comercios esta- bles o ambulatorios, los cuales no requirieron especialización alguna. También se emplearon como trabajadores domésticos. No hubo demasiadas resistencias culturales, integrándose, especialmente, a los sectores populares.

Juan de Arona dice que los chinos: “(...) resolvieron la cuestión de brazos, del servicio doméstico que hinchieron de una población laboriosa y flotante los valles y las haciendas de la costa, que llevaban su iniciativa industrial hasta los puntos más internos de la sierra y aún de la montaña, que determinaron el gran auge agrícola que por varios años disfrutó el Perú, que introdujeron multitud de menudas y nuevas industrias, que lo abarataron todo y que, debido a ello y sus fonditas de ínfimos precios, se acostumbró nuestra plebe a comer en manteles y usar cubiertos y vasos"38. A estas y otras virtudes que le atribuyeron a los chinos se agregaron otras, pero negativas, como su vicio para el juego, su sensualismo, su adicción al opio, etc.

Las fonditas, de bastante aceptación popular, después se convirtieron en pequeños restaurantes denominados "chifas" (que significa "comer") donde el alimento básico era el arroz, símbolo de su cultura y ahora parte indispensable de la comida peruana. La presencia china contribuyó también al desarrollo del comercio minorista, introduciendo la "yapa" como forma de atraer clientes y así vender más. Se afirma que fueron los promotores de laborar los domingos y feriados, incorporando un estilo austero de vida relacionado con el trabajo. También se les atribuyó la invención de los "panderos" como forma de ahorro y capi- 
talización.

Según Wilma Derpich, existieron dos mecanismos culturales de indiscutible eficacia que explicaba la incorporación de los chinos a la sociedad peruana: la formación de familias peruanas y la afirmación definitiva de su doble identidad ${ }^{39}$. Al igual que los españoles del siglo XVI, los inmigrantes chinos fueron casi en su totalidad varones, y propiciaron su unión conyugal con mujeres de otras etnias o razas. Con el tiempo, los chinos se "amestizaron" más y no constituyeron un grupo distinto evidente. Así numerosos elementos de su cultura, entre ellos los culinarios, fueron aceptados en nuestra sociedad. Jorge Basadre afirma que al margen del sombrío problema que representó esta mano de obra, desde fines del siglo XIX o comienzos del siglo $\mathrm{XX}$, se fue desarrollando una clase media china de base comercial; enriqueciéndose algunos de sus miembros en ese proceso.

\section{III.2 Europeos}

En el caso de los europeos, en un principio, la mayoría estaba destinada a la agricultura. Watt Stewart, refiriéndose al fracaso de estos inmigrantes en el agro costeño, dice que los grandes hacendados no querían "que el labrador el verdadero colono, se instalara en las zonas de agricultura. Su único interés era obtener mano de obra barata para trabajar sus tierras (...) El campesino europeo que llegaba al Perú quería con el tiempo ser dueño de su pedazo de tierra. Pero los salarios eran muy bajos y por consiguiente la posibilidad de ahorrar para poner un negocio o comprar tierra era muy limitada, a lo que hay que agregar la casi imposibilidad de obtener tierra fértil" ${ }^{40}$. El hacendado costeño se negaba a permitir que se usufructue una parcela de su propiedad a favor del colono, fuera éste indígena o extranjero. Por el contrario aspiraba a extender su territorio arrebatándole tierras a los pequeños propietarios. José Carlos Mariátegui también había señalado con anterioridad que "el latifundismo subsistente en el Perú se acusa, de otro lado, como la más grave barrera para la inmigración blanca" ${ }^{41}$.

A pesar de los intentos de colonización dirigida, la mayoría de europeos que llegaron al Perú lo hicieron por iniciativa propia. Después de una frustrada experiencia colonizadora, muchos se vincularon predominantemente a actividades comerciales, sobre todo, a aquellas de más rápido crecimiento económico. Desde fines del siglo pasado, surgió un grupo privilegiado de migrantes que diversificó sus intereses hacia los sectores minero, agrario o manufacturero. La atrasada estructura económica del país fue incapaz de proletarizar a muchos inmigrantes extranjeros, que constituían una fuerza de trabajo libre, muchos con destrezas, habilidades y calificaciones. Un grupo de ellos, por su cuenta, se insertó en actividades dejadas de lado por la clase económica nacional, aprovechando la carencia de un sector empresarial capitalista peruano.

La población inmigrante europea más numerosa estuvo formada por italianos, seguido de ingleses, franceses, españoles y alemanes. Las tendencias del asentamiento estuvieron marcadas por una alta concentración en Lima y Callao y, en menor medida, en otras ciudades, constituyendo 
importantes polos de atracción económica, pero también de concentración de los fracasos de las colonizaciones. Se afirma que la aparición de las primeras fábricas en el país estuvieron relacionados con los inmigrantes europeos: bebidas, chocolates, galletas, tabaco, confecciones, textiles, muebles, etc. Aun siendo pocos contribuyeron al desarrollo del capitalismo en el Perú.

La mayoría de pequeños establecimientos comerciales estuvieron en manos de italianos. Estos negocios eran tiendas de abarrotes conocidas como pulperías, chinganas y bodegas, siendo estas últimas más grandes y variadas. También había inmigrantes propietarios de tabernas, cafés, bares y restaurantes. Muchas bodegas funcionaban en la intersección de dos calles, siendo conocidos como los "italianos de la esquina". Ellos mismos incorporaron a nuestra alimentación varios elementos de su cultura culinaria como los tallarines (verdes y rojos), el menestrón, pastel de acelga, panetones, pan dulce, etc. Socializaron el consumo de vino, siendo los pioneros del cultivo de uvas de calidad. Algunos italianos formaron familias con peruanos de sectores populares.

A pesar de que la sociedad oligárquica presentaba escasos canales de movilidad social, un grupo de migrantes encontró formas de ascender, sustentadas en algunas ventajas como su experiencia, calificación, capitalización, emprendimiento, color de piel, apellidos "gringos", etc. que para muchos peruanos constituían expresión de la "superioridad" de la raza blanca. "Al provenir de sociedades capitalistas en expansión traían un bagaje técnico empresarial que les permitió ocupar el vacío co- mercial y empresarial inexistente en el país durante el siglo pasado. Quienes tuvieron más posibilidades de éxito fueron los que poseían ciertas habilidades técnicas (artesanos, carpinteros, técnicos, etc.) o los que tenían alguna posibilidad de instalar un negocio independiente" ${ }^{42}$. Estos europeos se emparentaron con familias oligárquicas y terratenientes locales. Sus descendientes contribuyeron a engrosar los sectores sociales medio y medio alto no sólo en función de actividades empresariales, sino también de una mayor profesionalización que fue para ellos un canal importante de movilidad social. La inmigración europea y su descendencia tuvieron una influencia importante en la formación del empresariado industrial peruano. La mayoría de propietarios extranjeros de las fábricas de Lima-Callao eran de ascendencia italiana.

Carlos Contreras afirma que la clase empresarial peruana a finales del siglo XIX se componía en un gran número de inmigrantes europeos: ingleses y austro-hungaros en la minería, italianos en la industria y la agricultura, españoles y franceses en el comercio. El circuito económico de esta clase de empresarios fue enteramente local y sus inversiones extranjeras ${ }^{43}$. Pero también su presencia se vislumbró en la política del país. Basadre dice que "el aporte de los sectores de población paterno o materno europeo no español en este país, no debe ser examinado desde el punto de vista numérico que es relativamente escaso sino en función de su facilidad para adaptarse y desenvolverse dentro del conglomerado social" ${ }^{\prime 4}$. El mismo autor menciona algunos apellidos paternos o maternos no españoles en los gabinetes del gobierno de Piérola (Almenara Butler), Romaña (Adrián Ward, 
Larrabure y Unanue, Teodoro Elmore y David Matto) y otros. En conclusión, un grupo importante de inmigrantes blancos se integraron al grupo denominado hispano-blanco occidental, vinculado al poder económico y político del país.

\section{III.4 El crecimiento demográfico}

Entre 1850 y 1876 , la población peruana transitó de 2’001,000 a 2'699,106 personas. Entre 1890 y 1900 pasó de 3'050,000 a 3'373,000, período que coincidió con los inicios de la recuperación económica del país ${ }^{45}$. La segunda mitad del siglo XIX se caracterizó por un lento crecimiento demográfico, siendo escaso el aporte de las migraciones extranjeras. Entre 1850 y 1876 , la población extranjera se habría incrementado de 45,000 a más de 100,000 personas. En 1860, basado en datos parciales y focalizados, se contabilizaron 2,200 extranjeros sólo en los departamentos de Huancavelica, Piura, Ica, Junín y Moquegua, pero excluyendo a las haciendas costeñas. Según estos datos, el $58 \%$ vivía en Moquegua, sobre todo, en la provincia de Tarapacá, el 19\% en Junín (en especial Cerro de Pasco) y el 12\% en Piura.

Según los resultados del IV censo nacional de población del año 1876, el número de extranjeros ascendió a 107,000 personas, el $4 \%$ del total de habitantes del país. Estas cifras, aunque poco significativas, tuvieron enorme importancia porque marcó el momento de mayor presencia foránea en la historia del Perú. Como se observa en el cuadro 2, entre los extranjeros predominaban los asiáticos (47\%), específicamente chinos, seguido de americanos (31.4\%) y en menor medida europeos (17\%).

La inmigración europea no fue masiva, hasta 1876 apenas superaba los 18,00 habitantes, mientras que los chinos fueron casi 50,000. Estas minorías étnicas representaban 0.7 y $1.9 \%$ de la población del país, respectivamente, mientras los americanos participaban con el $1.2 \%$. En general, la inmigración extranjera fue mayoritariamente masculina, siendo casi total en los chinos (99.4\%). Entre los europeos, la presencia femenina fue más significativa en los franceses (26.9\%) y alemanes (26.6). Entre los americanos, la proporción de mujeres fue más alta. Así destacaron las ecuatorianas (39.5\%), seguida de bolivianas (36.0) y chilenas (33.4).

La población europea más numerosa fue la italiana $(6,990)$, seguida de la inglesa $(3,379)$ y francesa $(2,647)$. Entre los americanos había más chilenos $(14,235)$ y bolivianos (12,321), muchos de ellos localizados en el sur del país, vinculados a la actividad salitrera. Antes de finalizar el siglo XIX, la población europea comenzó a descender.

Los extranjeros se concentraron en la provincia de Lima y constituyeron un componente importante de su crecimiento demográfico. En 1857, esta provincia tenía 94,195 habitantes. Los foráneos sumaban 21,557 (22.9\%) de ese porcentaje, el grupo de los europeos contaban con 13,208 personas; los americanos, 4,527; y los chinos, 2,830. Dentro de los europeos predominaban los alemanes (34\%), seguido de los italianos (27\%), franceses (21\%), españoles (11\%) e ingleses $(8 \%)$. En 1876, el número de extranjeros se in- 
crementó $(22,634)$, pero porcentualmente su participación declinó (18.5\%) con respecto a la población de la provincia de Lima (172,927 habitantes). En esos años, los europeos disminuyeron a 6,749 personas y los chinos aumentaron a 12,000. Entre 1857 y 1876 se pasó del predominio europeo al predominio asiático, situación que se mantuvo hasta finalizar el siglo XIX. Cabe destacar que en Lima habitaba el $37 \%$ del total de europeos y un $24 \%$ de los chinos.

\section{Las migraciones extranjeras en las primeras décadas del siglo XX}

En las primeras décadas del siglo XX, en el Perú, la economía se recuperó y expandió como consecuencia de la monopolización de los recursos, de la desnacionalización de la propiedad y del inicio masivo de la inversión directa de capitales extranjeros. Los sectores claves de la economía fueron la agricultura costeña y la minería andina, cuyas exportaciones se incrementaron sobre manera durante la Primera Guerra Mundial. En lo político, se operó un retorno de los civiles al poder, luego de los gobiernos militares posteriores a la Guerra del Pacífico. Para Jorge Basadre estos años fueron el periodo de la "República aristocrática”.

Desde fines del siglo XIX, las haciendas costeñas requirieron de mayor mano de obra que ya no podían obtener de los culís chinos. Sin embargo, en un último esfuerzo se intentó revivir la migración asiática de chinos y japoneses destinada a la agricultura, mientras la inmigración europea disminuía. En el período del oncenio de Leguía (1919-1930), las migraciones de japoneses continuaron. W. Derpich afirma que Leguía "preocupado por la falta de braceros, será un defensor permanente de inmigraciones asiáticas, según otras condiciones, según las cuotas establecidas por su propio gobierno"46. Las migraciones niponas decayeron con la vuelta de los militares al poder (1930-1939). Entre 1920 y 1940, la economía estuvo marcada por un proceso de crecimiento, crisis mundial y recuperación, dentro de un contexto de hegemonía de capitales norteamericanos.

Aunque escaso, el aporte migratorio extranjero presentaba algunas tendencias importantes. En la primera mitad del siglo XX, su contribución fluctuó entre lo irrelevante y lo irrisorio. Los censos de 1876 y de 1940 dan cuenta de un descenso del número de extranjeros de 107,000 a 62,680 , también su participación relativa declinó de $4 \%$ a un escaso $1 \%$ de la población del país*.

En las primeras décadas del siglo XX, los movimientos migratorios se caracterizaron por un descenso de las migraciones extranjeras (sobre todo china y europea) y un mayor aumento de las migraciones nativas o internas y tuvieron en el sistema del enganche sus principales manifestaciones.

\section{IV.1 La inmigración china}

En 1904, en un intento por reactivar la inmigración asiática, arribó al Perú el primer buque, trayendo poco más de trescientos trabajadores chinos. En 1905, siguieron llegando, pero en menor cantidad. En realidad, el ciclo migratorio chino había terminado con funestas consecuencias en la mayoría de los casos. 
Entre 1890 y 1930, puede decirse que hubo una segunda pero reducida oleada migratoria china. Pero los que llegaron a diferencia de los anteriores, en su mayoría traían capitales para invertir. Ellos instalaron casas comerciales en Lima, posteriormente abrieron compañías de seguros, firmas navieras y arrendaron o compraron propiedades agrícolas, principalmente para el cultivo del algodón y azúcar. Estos inmigrantes comenzaron con el comercio y rápidamente ingresaron a la agricultura, industria y finanzas. Simultáneamente, en ese mismo período, los chinos de la primera inmigración (1850-1874) trabajaron en algunas haciendas como contratados, yanaconas y arrendatarios o como pequeños comerciantes en diversos lugares del país ${ }^{47}$.

\section{IV.2 La inmigración japonesa}

La presencia de japoneses en el Perú se inició en 1899 y se incrementó en los siguientes años, en la medida que fueron disminuyendo los chinos y europeos. La llegada de japoneses constituyó la última y más importante ola migratoria destinada a suministrar mano de obra a la agricultura.

Los japoneses numéricamente fueron los segundos en importancia después de los chinos. Para traer contingentes de trabajadores japoneses, los propietarios de las haciendas y los suministradores (compañías con fuerte presencia del Estado japonés) estipularon condiciones que señalaban, entre otras, que los inmigrantes tuvieran de 25 a 45 años, que recibieran alojamiento y asistencia médica y los hombres 2.5 libras esterlinas mensuales por diez horas diarias de trabajo en el campo y 12 en las fábricas. Los gastos del viaje a razón de 10 libras por individuo correrían por cuenta del hacendado si se trataba de hombres y de los maridos si se trataba de mujeres. El viaje de vuelta una vez concluido el contrato lo costeaba la agencia cuyo representante en el Perú era el único intermediario para las relaciones entre hacendado y colono.

El 3 de abril de 1899, el buque "Sakura Maru” arribó al Perú trayendo a bordo 787 inmigrantes, con contratos de trabajo de 4 años en las haciendas azucareras y algodoneras. En los siguientes años, fueron arribando más, en 1910 sumaban 6,734 japoneses. Según el cuadro 3, entre 1899 y 1923, ingresaron al Perú alrededor de 16,687 braceros japoneses en calidad de contratados, aunque con mujeres y niños ascendieron a 18,258. A diferencia de los chinos, muchos japoneses vinieron con sus familias. En 1908 llegó el mayor contingente de inmigrantes $(2,608)$.

La inmigración japonesa formaba parte de una política de población dirigida por el Estado de ese país. Se enviaron contingentes de personas a distintos lugares del mundo (Corea, Manchuria, Estados Unidos, Canadá, etc.) para amortiguar el rápido crecimiento demográfico de este país y también ampliar sus áreas de influencia. La colonia nipona que se formó en el Perú, social y culturalmente, fortaleció sus vínculos con la madre patria, la cual ejercía una gran influencia, constituyendo una comunidad bastante aislada del contexto nacional en que se encontraban. Esto generó el rechazo de una parte de la población peruana, alarmada también por sus éxitos económicos. 
De acuerdo con sus contratos, estos inmigrantes fueron conducidos a trabajar a las haciendas de los valles de Cañete, Chancay, Zaña, Pativilca, Supe, Lambayeque y a los alrededores de Lima, como Puente Piedra. En todos estos valles y ciudades, aún hoy en día, existen comunidades de japoneses y de sus descendientes. Los japoneses no experimentaron los abusos violentos del que fueron objeto los inmigrantes chinos, aunque si padecieron engaños y humillaciones. "Si bien en un primer momento estuvieron bien pagados (al punto de soñar regresar a su país), pronto vieron reducidos sus contratos de trabajo a destajo, mal remunerado. Muchos de ellos rechazaron las condiciones de trabajo impuestas (pago en bonos y no en dinero, incumplimiento de los horarios de trabajo, problemas con la alimentación, etc. $)^{48}$.

La inmigración bajo contrato concluyó oficialmente en 1924. Pero, durante el periodo 1924-1930, arribaron más japoneses al Perú, aproximadamente 8,000, que llegaron a través del "yobiyose imig" o inmigración por llamado, animados por los primeros inmigrantes dedicados en su mayoría al comercio en Lima y Callao o a la agricultura en la costa. El cese de la migración por contrato se produjo debido al bajo nivel salarial, ineficaz para atraer nuevos inmigrantes y también porque a fines de 1930 ya no fue necesaria la importación de mano de obra. En 1931, la colonia japonesa constituía la población extranjera más numerosa.

Según Amalia Morimoto, en 1930 la población de origen nipón, entre inmigrantes y descendientes, sumaba 20,295 personas. De esta cifra, 17,725 residían en
Lima y el resto se encontraba distribuida en diferentes departamentos de la costa, sierra y selva ${ }^{49}$. Muchos se convirtieron de trabajadores asalariados en la agricultura a trabajadores independientes, bajo la forma de pequeńos y medianos propietarios de tierras, yanaconas y arrendatarios. "Los agricultores independientes, cuya cifra fue elevándose de 1,145 en 1923 hasta 1,929, se dedicaron inicialmente al cultivo de pan llevar para pasar posteriormente al cultivo de algodón; debido a la forma de explotación que requería este producto su cultivo se extendió aún entre los pequeños productores. Por otro lado, las actividades como yanaconas tuvieron un especial significado para el desarrollo de la producción algodonera y la modernización de las haciendas del valle de Chancay" ${ }^{50}$. Los japoneses en el campo introdujeron nuevas tecnologías, formas de organización empresarial, racionalizaron el uso del agua, ampliaron áreas de cultivo, etc.

Un gran número de trabajadores japoneses, al igual que chinos, dejaron después las plantaciones y se volcaron a la capital de la república. En un primer momento, como mano de obra barata en las actividades de comercio, servicios y manufacturas, reproduciendo en la ciudad su condición de asalariados, incrementando la oferta de trabajo y contribuyendo a constreñir los ingresos, deteriorando de esta manera las posibilidades económicas de los sectores laborales urbanos. Esto provocó la protesta de grupos de trabajadores peruanos afectados por esta forma de competencia. Pero después de un tiempo, muchos japoneses, al igual que los chinos, se convirtieron en trabajadores independientes, siendo propietarios de pequeños negocios 
(tienda de abarrotes, restaurantes, bazares, peluquerías, etc.).

Fue relevante la presencia de esta comunidad en la capital de la República, pero la competencia impuesta por los comerciantes japoneses a los bodegueros peruanos, así como el crecimiento del número de yanaconas japoneses en las grandes propiedades algodoneras constituyeron elementos de descontento que estimularon un racismo antinipón, con manifestaciones violentas surgidas entre diciembre de 1930 y agosto de 1931, justamente con la crisis mundial del capitalismo. Esta situación se agravó en la Segunda Guerra Mundial cuando muchos japoneses fueron despojados de sus propiedades y expulsados del país.

\section{IV.3 Declive de la inmigración europea}

En los primeros años del siglo XX, la inmigración europea prácticamente llegaba a su fin. Los resultados por atraer en gran número inmigrantes blancos desde mediados del siglo XIX fueron precarios. En 1902, los europeos se habrían reducido a 13,200 habitantes, de los cuales 5,638 eran italianos, es decir más del $40 \%$. A diferencia de los chinos, los europeos arribaron al Perú para colonizar tierras, pero no tuvieron grandes éxitos debido entre otras causas a: 1. el incumplimiento por parte del Estado peruano y otros particulares de las obligaciones contraídas con los colonos, lo cual le restó credibilidad a sus mismos Decretos-Leyes, 2. las condiciones adversas y difíciles que hubieron para viajar sobre todo a la selva, 3 . la inestabilidad política que reinaba en el país, y 4. terratenientes dueños de gran- des extensiones de tierras, especialmente en la costa, que no querían compartirlas con los colonos, negándoles algunas parcelas. Estos propietarios no querían colonos sino braceros. Buscaban mano de obra barata, condición que el europeo no aceptó. Basadre afirma que a pesar del gran interés del gobierno de José Pardo por estimular la inmigración blanca, esta no se produjo en gran escala.

A todo esto habría que agregar la cercanía geográfica que tenían algunos países de América para captar con más éxito a una numerosa migración europea, como fueron los casos de Argentina, Uruguay y Brasil, cuyas costas en el Oceano Atlántico se encontraban al frente de Europa. A manera de referencia, se calcula "que los europeos que migraron a Estados Unidos entre 1824 y 1924 sumaron aproximadamente 37 millones de personas, los que se establecieron en Argentina entre 1857 y 1928, fueron aproximadamente 6 millones 130 mil y los que se dirigieron a Brasil entre 1884 y 1933 , aproximadamente 3 millones 690 mil personas" 51 .

Después de la guerra civil en España y antes de la Segunda Guerra Mundial, arribaron al Perú grupos reducidos de refugiados españoles y judíos. El término de la Segunda Guerra Mundial también produjo la inmigración de pequeños grupos de europeos que arribaron en calidad de refugiados de acuerdo al convenio que hubo entre el gobierno peruano y la Organización Intergubernamental de Refugiados (OIR). Entre febrero 1948 y marzo de 1949 arribaron al Perú 1,927 personas entre hungaros, italianos, serbios, croatas, alemanes, etc. $^{52}$ 


\section{IV.4 La migración extranjera en Lima- Callao}

Muchos extranjeros (asiáticos y europeos) se movilizaron a la capital de la República, después de haber experimentado las frustraciones de su permanencia en el campo. Por tal razón su presencia en Lima tuvo una mayor resonancia demográfica, incluso social y económica. Por ejemplo, ellos contribuyeron a diversificar, dinamizar y modernizar diferentes actividades productivas, ya sea comerciales, industriales o de servicios.

Baltazar Caravedo señala que los inmigrantes extranjeros fueron propietarios de numerosos establecimientos industriales, destacando los italianos como núcleo predominante, siendo probable que el Banco Italiano los apoyara. En 1931, el 15\% de los inmigrantes de Lima se dedicaban a la industria y el $34.6 \%$ al comercio. De este porcentaje, destacaban los italianos como los propietarios más representativos. Los japoneses se dedicaron en mayor medida al comercio ${ }^{53}$.

En términos demográficos, por estos años, se notó una tendencia decreciente de los extranjeros en Lima, que tenía correspondencia con el descenso de la inmigración internacional en el Perú. En 1908, los extranjeros en la provincia de Lima disminuyeron a 16,531 (en la ciudad fueron 13,308), también su participación relativa $(9.6 \%)$. En su mayoría eran asiáticos (46\%), seguido de europeos (36.4\%). En 1920, la población foránea siguió descendiendo a $15,957^{54}$, así como su porcentaje (7.1\%) con relación al total de habitan- tes de la provincia (ver cuadro 4). En los periodos 1876-1908 y 1908-1920 la tasa de crecimiento demográfica foránea fue negativa $(-1.0 \%$ y $-0.3 \%$, respectivamente). Japoneses y chinos fueron los grupos étnicos con mayor población en la capital, pero también los principales afectados por las deficientes condiciones de habitabilidad. Por ejemplo, el actual barrio chino era un conjunto de tugurios, siendo bastante conocido el callejón de Otaiza, donde en 100 cuartos vivían apiñados más de 1,000 asiáticos.

En 1931, la población extranjera en Lima aumentó a 24,610 personas, aunque su participación relativa cayó (6.6\%). Este hecho estuvo relacionado con el incremento de la migración nipona, manteniéndose como la población foránea más numerosa con 9,783 personas, seguida de la china con 5,404 e italiana con 3,853. En 1940, los extranjeros sumaban más de 28,000 personas, pero representando el $5.3 \%$ de la población de la provincia de Lima. El $51 \%$ de los inmigrantes eran asiáticos y el $28 \%$ europeos. Hay que señalar que en esta provincia se concentraba el $45 \%$ del total de la migración extranjera.

Según Carlos Contreras, los esfuerzos que realizó el Estado por atraer extranjeros al Perú, entre el siglo XIX y XX, duraron entre siete u ocho décadas. En ese tiempo llegaron aproximadamente 200,000 personas, cifra modesta comparada con los inmigraron a otros países latinoamericanos ${ }^{55}$.

\section{Conclusiones}

1. En el periodo 1821-1850, en un contexto de crisis y recuperación eco- 
nómica, se dieron un conjunto de leyes favorables para la inmigración europea, porque eran considerados "una garantía necesaria y natural para el desarrollo del país". La élite dominante, que sustentaba la creencia de la superioridad de la raza blanca, quería redefinir y legitimar las diferencias sociales dentro del nuevo ordenamiento jerárquico de la República. Tanto en el período de crisis económica y caos político que vivió el Perú entre 1821-1840, así como en los inicios del boom guanero en la década de 1840, se fomentó la llegada de europeos, aunque en su mayoría los que arribaron fueron ajenos a las leyes migratorias.

2. Entre 1850 y 1875 , en un contexto de bonanza económica, debido a las exportaciones del guano, el Estado peruano de manera más organizada, se propuso traer más inmigrantes europeos para colonizar tierras, pero la gran mayoría de los que vinieron fueron "chinos" para trabajar como peones en la haciendas de la costa, constituyendo "la verdadera inmigración”. Los grupos de poder económico querían braceros no colonos. En este periodo, la inmigración extranjera fue más numerosa con relación a otros tiempos, aunque tuvo poca incidencia en el crecimiento demográfico del país.

3. En las últimas décadas del siglo XIX y primeras décadas del siglo $\mathrm{XX}$, en otro contexto, pero de recuperación y crecimiento económico, se acentuó el declive de la inmigración europea y china, a pesar de los intentos para atraerlos. Para atenuar el déficit de mano de obra en la agricultura, se incrementó la inmigración japonesa, insertándose muchos como parceleros y yanaconas. Por esos años, fueron creciendo las migraciones internas, reemplazando a los chinos en las haciendas de la costa.

4. Si bien la mayoría de inmigrantes extranjeros que llegaron al Perú, sobre todo, a partir de 1850 fue para trabajar en la agricultura (como peones, colonos, parceleros o yanaconas), en la práctica a través de un proceso se vincularon a diferentes actividades no agrícolas, especialmente localizadas en Lima, debido a que terminaron sus contratos (en el caso de los chinos) y a las condiciones adversas que existieron (casos de europeos y japoneses. Sólo destacó una ínfima minoría de europeos (alemanes e italianos) que colonizaron tierras en la selva alta.

5. En la capital, el aporte de las migraciones extranjeras tuvo un mayor impacto demográfico, así también fue más tracendente su contribución a la diversificación, expansión y modernización de las actividades económicas. Muchos extranjeros se movilizaron a la ciudad de Lima después de experimentar sus fracasos en la agricultura.

6. Siendo poco numerosa la cantidad de inmigrantes extranjeros (en especial europeos), su contribución al desarrollo del capitalismo en el Perú 
resultó importante, observándose su aporte en las ramas de la agricultura, industria, finanzas, comercio, servicios, etc. También fue evidente su presencia en la cultura y política de nuestra sociedad.

\section{Notas}

(1) ALTAMIRANO, Teófilo. Migración el fenómeno del siglo. PUCP. Fondo Editorial. Lima, 1996. Pág. 23.

(2) YEPES DEL CASTILLO, Ernesto. Perú 1820-1920. Un siglo de desarrollo capitalista”. IEP. Lima, 1972. Pág. 35.

(3) OLIART, Patricia. Poniendo a cada quien en su lugar: estereotipos raciales y sexuales en la Lima del siglo XIX. En Mundos interiores. Lima 18501950, CIUP, 1995. Pág. 262.

(4) OLIART, Patricia. Ob. Cit. Pág. 264.

(5) WATT, Stewart. La servidumbre china en el Perú. Edit. Mosca Azul. Lima, 1976. Pág. 22.

(6) BASADRE, Jorge. Historia de la RepúblicadelPerú.Edit.Universitária. Lima, 1969. T. I. Pág. 231.

(7) DE ARONA, Juan. La inmigración en el Perú. Monografía histórico-crítica. Imprenta Universo. Lima, 1891. Págs. 241-242.

(8) DE ARONA, Juan. Ob. Cit. Pág. 242.

(9) HUNEFELDT, Christine. Inserción socio-económica de los extranjeros en el Perú: Una interpretación de los datos censales entre 1840 y 1870 . En Primer Seminario sobre poblaciones inmigrantes, CONCYTEC. Lima, 1986. Pág. 144.

(10) DE ARONA, Juan. Ob. Cit. Pág. 242

(11) DE SARTIGES-BOTMILLAU. Viajeros en el Perú. Dos viajeros franceses en el Perú republicano. Edit.
Cultura Antártica en el Perú. Lima, 1947. Págs. 214-215.

(12) OLIART, Patricia. Ob. Cit. Pág. 270.

(13) VON TSCHUDI, J. Ob. Cit. Págs. 105 y 121.

(14) LEVIN, Jonathan. Las economías de exportación. Edit. UTEHA. México, 1964. Págs. 48-49.

(15) BASADRE, Jorge. Ob. Cit., T.III.

Pág. 192.

(16) STEWART, Watt. La servidumbre china en el Perú. Edit. Mosca Azul. Lima, 1976. Pág. 26.

(17) BASADRE, Jorge. Ob. Cit. Pág. 324.

(18) YAMAWAKI, Chikako, citando a Rodríguez Pastor, dice "que para los esclavos negros que hasta ese entonces ocupan el estrato más bajo de la sociedad, la existencia de los inmigrantes chinos en una posición inferior a la de ellos fue un gran consuelo", en "Estrategias de vida de los inmigrantes asiáticos en el Perú". IEP. Lima, 2002. Pág. 34.

(19) LEVIN, Jonathan. Ob. Cit. Pág. 97

(20) UGARTE, César Antonio. Bosquejo de la historia económica del Perú. Lima, 1926, reproducido por Delva Editores. Pág. 63.

(21) WAT, Stewart. Ob. Cit. Pág. 180.

(22) ESTEVES, Luís. Apuntes para la historia económica del Perú, reproducida por el CEPD. Lima, 1971. Págs. 7-8.

(23) BASADRE, Jorge. Ob. Cit., Tomo VII. Pág. 102.

(24) Tomado de la "Inmigración de chinos" de César Borja, citado por Watt Stewart en "La servidumbre en el Perú”. Pág. 31.

(25) BONFIGLIO, Giovanni. Introducción al estudio de la inmigración europea en el Perú. En Primer seminario sobre poblaciones inmigrantes. CONCYTEC. Lima, 1987. Pág. 35.

(26) BASADRE, Jorge. Ob. cit. T.IV. Pág. 366. 
(27) BURGA, Manuel. Ob. Cit. Pág. 170.

(28) BASADRE, Jorge. Ob. Cit. T.III. Págs. 324-325.

(29) DE ARONA, Juan. Ob. Cit. Pág. 64.

(30) DE ARONA, Juan. Ob. Cit. Pág. 65.

(31) BASADRE, Jorge. Ob. Cit. Pág. 103.

(32) HUNERFELDT, Christine. Ob. Cit. Pág. 147.

(33) GODBERSEN, Guillermo. La inmigración inglesa en el Perú. Edic. Servicios Generales René S.A.C. Lima, 2006. Pág. 47.

(34) BARDELLA, Gianfranco. Setenticinco años de vida económica en el Perú. Banco de Crédito del Perú. Lima, 1964. Pág.19.

(35) Tomado de Abraham Padilla "La Historia de la Inmigración en el Perú", como complemento de la obra de Juan de Arona "La inmigración en el Perú”. Pág. 246.

(36) BASADRE, Jorge. Ob. Cit. T.IX. Pág. 245

(37) BASADRE, Jorge. Ob. Cit. T.IX. Pág. 245

(38) DE ARONA, Juan. Ob. Cit. Pág. 34

(39) DERPICH, Wilma. El otro lado azul. 150 años de inmigración china al Perú. Fondo Editorial del Congreso del Perú. Lima, 2000. Pág. 119.

(40) STEWART, Watt. Ob. Cit. Pág. 23.

(41) MARIÁTEGUI, José C. Siete ensayos de interpretación de la realidad peruana. Ediciones populares. Lima, 1959. Pág. 86.

(42) BONFIGLIO, Giovanni. Ob. Cit. Pág .52

(43) CONTRERAS, Carlos. La inversión extranjera en el Perú 1890-1930. Un
Estado de la cuestión. En Revista Alma Mater, $\mathrm{N}^{\circ}$ 5, UNMSM. Lima, 1993. Pág. 88.

(44) BASADRE, Jorge. Ob. Cit. T.XVI. Pág. 235.

(45) OFICINA NACIONAL DE ESTADÍSTICA Y CENSOS. Primer volumen del Censo Nacional de Población y Ocupación, 1940. Lima, 1944.

(46) DERPICH, Wilma. Ob. Cit. Pág. 28.

(47) DERPICH, Wilma. Ob. Cit. Pág. 17.

(48) LAUSENT-HERRERA, Isabelle. Pasado y presente de la comunidad japonesa en el Perú. IEP. Lima, 1971. Pág. 17.

(49) MORIMOTO, Amalia. Población de origen japonés. Investigaciones y bibliografía. CONCYTEC. Lima, 1986. Pág. 121.

(50) MORIMOTO, Amalia. Ob. Cit. Págs. 121-122.

(51) YAMAWAKI, Chikako. Ob. Cit. Pág. 47.

(52) PADILLA, Abraham. Historia de la inmigración en el Perú. En La inmigración en el Perú de Juan de Arona. Pág. 238

(53) CARAVEDO, Baltazar. Economía, producción y trabajo. Perú siglo XX. En Historia del Perú Republicano, T.8, Edit. Juan Mejía Baca. Lima, 1980. Pág. 227.

(54) Según Burga y Flores, Lima en 1920 tenía 20,000 extranjeros, de los cuales menos de 1,000 eran ingleses y 3,000 italianos. Más numerosa fue la colonia china que superaba las 5,000 personas, pero ocupando el primer lugar se encontraban 9,000 japoneses. En "Apogeo y crisis de la República aristocrática”. Edic. Rikchay. Lima, 1984. Pág. 17.

(55) CONTRERAS, Carlos. Sobre los orígenes de la explosión demográfica en el Perú: 1876-1940. IEP. Lima, 
1994. Pág. 17.

\section{BIBLIOGRAFÍA}

ALTAMIRANO, Teófilo. Migración el fenómeno del siglo. Lima, PUCP, Fondo Editorial, 1996.

BASADRE, Jorge. Historia de la República del Perú. Lima, Editorial Universitaria, 1969.

BONFIGLIO, Giovanni. Introducción al estudio de la inmigración europea en el Perú. En Primer Seminario sobre poblaciones inmigrantes en Lima. Lima, CONCYTEC, 1986.

BURGA, Manuel. De la encomienda a la hacienda capitalista. Lima, IEP, 1976.

BURGA, Manuel y FLORES GALINDO, Alberto. Apogeo y crisis de la República Aristocrática. Lima, Edit. Rikchay, 1984.

CARAVEDO, Baltazar. Economía, producción y trabajo. Perú siglo XX. En: Historia del Perú Republicano. Lima, Editor Juan Mejía Baca, 1980.

CONTRERAS, Carlos. La inversión extranjera en el Perú: 1890-1930. Un Estado de la cuestión. En: Revista Alma Mater No. 5. Lima, 1993.

CONTRERAS, Carlos. Sobre los orígenes de la explosión demográfica en el Perú: 18761940. Lima, IEP, 1994.

DE ARONA, Juan. La inmigración en el
Perú. Monografía Histórica-crítica. Lima, Imprenta Universo, 1981.

DERPICH, Wilma. El otro lado azul. 150 de inmigración china en el Perú. Lima, Editorial del Congreso del Perú, 2000.

DE SARTIGES-BOTMIMILLAU. Viajeros en el Perú. Dos franceses en el Perú Republicano. Lima, Edit. Cultura Antártica S.A., 1947.

ESTEVES, Luís. Apuntes para la historia económica del Perú. Lima, CEPD, 1971.

GODBERSEN, Guillermo. La inmigración inglesa en el Perú. Lima, Edic. Servicios Generales René S.A.C., 2006.

HUNEFELDT, Christine. Inserción socioeconómica de los extranjeros en el Perú: una interpretación de los datos censales entre 1840 y 1870 . En: Primer Seminario sobre poblaciones inmigrantes. Lima, CONCYTEC, 1986.

LEVIN, Jonathan. Las economías de exportación. México, Edit. UTHEA, 1964.

LAUSENT-HERRERA, Isabelle. Pasado y presente de la comunidad japonesa en el Perú. Lima, IEP, 1971.

MARIÁTEGUI, José Carlos. Los siete ensayos de interpretación de la realidad peruana. Lima, Ediciones Populares, 1959.

MORIMOTO, Amalia. La población de origen japonés en el Perú. Investigaciones y bibliografía. Lima, CONCYTEC, 1986.

OLIART, Patricia. Poniendo a cada quien en su lugar: Estereotipos raciales y sexuales en la Lima del siglo XIX. En: Mundos interiores: Lima 1850-1950. Lima, CIUP, 1995.

UGARTE, César. Bosquejo de la historia 
económica del Perú. Lima, reproducido por Delva Editores, 1926.

VON TSCHUDI, J. Testimonios del Perú: 1838-1842. Lima, Talleres Gráficos P.L. Villanueva, 1966.
YAMAWAKI, Chikako. Estrategias de vida de los inmigrantes asiáticos en el Perú. Lima, IEP-JCAS, 2002.

YEPES, Ernesto. Perú 1820-1920- Un siglo de Desarrollo capitalista. Lima, IEP, 1972.

YEPES, Ernesto. Los inicios de la expansión capitalista en el Perú: 1890-1930. En: La 
Historia del Perú. s/n.

STEWART, Watt. La servidumbre china en el Perú. Lima, Mosca Azul Editor, 1976.

\section{ANEXOS}

\section{CUADRO No 1}

INMIGRACIÓN CHINA EN EL PERÚ: 1850-1874

\begin{tabular}{|c|c|c|c|c|}
\hline \multirow[t]{2}{*}{ AÑOS } & \multirow[t]{2}{*}{$\begin{array}{l}\text { EMBARCADOS } \\
\text { EN MACAO }\end{array}$} & \multicolumn{2}{|c|}{$\begin{array}{l}\text { MUERTOS DURANTE } \\
\text { EL VIAJE }\end{array}$} & \multirow[t]{2}{*}{$\begin{array}{l}\text { DESEMBARCADOS EN EL } \\
\text { CALLAO }\end{array}$} \\
\hline & & Absolutas & $\%$ & \\
\hline TOTAL & 97,569 & 9,704 & 9.91 & 87,952 \\
\hline $1850-1860$ & 15,000 & 2,000 & 29.60 & 13,000 \\
\hline 1860 & 2,007 & 594 & 29.60 & 1,413 \\
\hline 1861 & 1,860 & 420 & 22.58 & 1,440 \\
\hline 1862 & 1,726 & 718 & 41.60 & 1,008 \\
\hline 1863 & 2,301 & 673 & 29.25 & 1,628 \\
\hline 1864 & 7,010 & 600 & 8.56 & 6,410 \\
\hline 1865 & 4,794 & 254 & 5.30 & 4,540 \\
\hline 1866 & 6,543 & 614 & 9.38 & 5,929 \\
\hline 1867 & 2,400 & 216 & 9.00 & 2,184 \\
\hline 1868 & 4,732 & 466 & 9.85 & 4,266 \\
\hline 1869 & 3,006 & 75 & 2.50 & 2,931 \\
\hline 1870 & 7,917 & 373 & 4.71 & 7,544 \\
\hline 1871 & 12,526 & 741 & 5.92 & 11,812 \\
\hline 1872 & 14,505 & 1,114 & 7.68 & 13,391 \\
\hline 1873 & 7,303 & 732 & 10.02 & 6,571 \\
\hline 1874 & 3,939 & 114 & 2.89 & 3,825 \\
\hline
\end{tabular}

FUENTE. Martinet, J.B.H. “'L'agricultere au Pérou, Resume du mémoire presenté au cóngres Internacional de 
Lagriculture", París, au Siege de la Societé, 1878, pag. 32. Tomado de Ernesto Yepes, "Los inicios de la expansión mercantil capitalista en el Perú: 1890-1930", en "la Historia del Perú”, T.VII, pag. 331.

\section{CUADRO No 2}

PERÚ: POBLACIÓN EXTRANJERA SEGÚN NACIONALIDAD: 1876 (Cifras Absolutas y Relativas)

\begin{tabular}{|l|c|c|c|c|c|c|}
\hline \multirow{2}{*}{ EXTRANJEROS } & \multicolumn{2}{c|}{ TOTAL } & \multicolumn{2}{c|}{ HOMBRES } & \multicolumn{2}{c|}{ MUJERES } \\
\cline { 2 - 7 } & Absoluta & $\mathbf{9}$ & Absoluta & \% & Absoluta & \% \\
\hline \multicolumn{1}{|c|}{ TOTAL } & $\mathbf{1 0 6 , 9 3 4}$ & $\mathbf{1 0 0 . 0}$ & $\mathbf{9 0 , 7 4 5}$ & $\mathbf{8 4 . 9}$ & $\mathbf{1 6 , 1 8 9}$ & $\mathbf{1 5 . 1}$ \\
\hline ASIATICOS & $\mathbf{4 9 , 9 9 8}$ & $\mathbf{4 6 . 8}$ & $\mathbf{4 9 , 6 8 5}$ & $\mathbf{9 9 . 4}$ & $\mathbf{3 1 3}$ & $\mathbf{0 . 6}$ \\
\hline Chinos & 49,979 & 46.7 & 49,668 & 99.4 & 311 & 0.6 \\
\hline Otros & 19 & - & 17 & 89.5 & 2 & 10.5 \\
\hline EUROPEOS & $\mathbf{1 8 , 0 8 5}$ & $\mathbf{1 6 . 9}$ & $\mathbf{1 4 , 8 6 9}$ & $\mathbf{8 2 . 2}$ & $\mathbf{3 , 2 1 6}$ & $\mathbf{1 7 . 8}$ \\
\hline Alemanes & 1,672 & 1.5 & 1,227 & 73.4 & 445 & 26.6 \\
\hline Espańoles & 1,699 & 1.6 & 1,385 & 81.5 & 314 & 8.5 \\
\hline Franceses & 2,647 & 2.5 & 1,934 & 73.1 & 713 & 26.9 \\
\hline Ingleses & 3,379 & 3.2 & 2,965 & 87.7 & 414 & 12.3 \\
\hline Italianos & 6,990 & 6.5 & 5,832 & 83.4 & 1,158 & 16.6 \\
\hline Otros* & 1,698 & 1.6 & 1,526 & 89.8 & 172 & 9.2 \\
\hline AMERICANOS & $\mathbf{3 3 , 6 1 2}$ & $\mathbf{3 1 . 4}$ & $\mathbf{2 2 , 0 7 2}$ & $\mathbf{6 5 . 7}$ & $\mathbf{1 1 , 5 4 0}$ & $\mathbf{3 4 . 3}$ \\
\hline Norteamericanos & 1,132 & 1.1 & 951 & 84.0 & 181 & 16.0 \\
\hline Chilenos & 14,235 & 13.3 & 9,483 & 66.6 & 4,752 & 33.4 \\
\hline Bolivianos & 12,321 & 11.5 & 7,877 & 63.9 & 4,444 & 36.1 \\
\hline Ecuatorianos & 4,086 & 3.8 & 2,472 & 60.5 & 1,614 & 39.5 \\
\hline Otros** & 1,838 & 1.7 & 1,289 & 70.1 & 549 & 29.1 \\
\hline OTROS & $\mathbf{5 5}$ & $\mathbf{0 . 1}$ & $\mathbf{4 7}$ & $\mathbf{8 5 . 5}$ & $\mathbf{8}$ & $\mathbf{1 4 . 5}$ \\
\hline IGNORADA & $\mathbf{5 , 1 8 4}$ & $\mathbf{4 . 8}$ & $\mathbf{4 , 0 7 2}$ & $\mathbf{7 8 . 5}$ & $\mathbf{1 , 1 1 2}$ & $\mathbf{2 1 . 5}$ \\
\hline \multirow{2}{*yyyyyyy}{} & & & & & & \\
\hline
\end{tabular}

FUENTE: Dirección General de Estadística. Censo General de la República del Perú, 1876

* Incluye a austriacos, belgas, daneses, portugueses, irlandeses, suecos, escoceses, etc.

** Incluye brasileños, colombianos, mejicanos, cubanos, etc.

Elaboración propia 
CUADRO No 3

PERÚ: ARRIBO ANUAL DE INMIGRANTES JAPONESES: 1899-1923

\begin{tabular}{|c|c|c|c|c|c|}
\hline \multirow{2}{*}{ AÑO } & \multirow{2}{*}{ No DE HOMBRES } & \multirow{2}{*}{ No DE MUJERES } & \multirow{2}{*}{ No DE NIÑOS } & \multicolumn{2}{|c|}{ TOTAL } \\
\cline { 5 - 6 } & & & & Absoluta & \% \\
\hline TOTAL & $\mathbf{1 6 , 6 8 7}$ & $\mathbf{2 , 1 4 5}$ & $\mathbf{2 2 6}$ & $\mathbf{1 8 , 2 5 8}$ & $\mathbf{1 0 0 . 0}$ \\
\hline $\mathbf{1 , 8 9 9}$ & 787 & - & - & 787 & 4.3 \\
\hline $\mathbf{1 , 9 0 3}$ & 1,160 & 110 & - & 1,270 & 7.0 \\
\hline $\mathbf{1 , 9 0 6}$ & 586 & 9 & 1 & 596 & 3.3 \\
\hline $\mathbf{1 , 9 0 7}$ & 450 & 1 & - & 451 & 2.5 \\
\hline $\mathbf{1 , 9 0 8}$ & 2,362 & 82 & 4 & 2,448 & 13.4 \\
\hline $\mathbf{1 , 9 0 9}$ & 694 & 28 & 1 & 723 & 4.0 \\
\hline $\mathbf{1 , 9 1 0}$ & 447 & 11 & 1 & 459 & 2.5 \\
\hline $\mathbf{1 , 9 1 1}$ & 222 & 29 & - & 251 & 1.4 \\
\hline $\mathbf{1 , 9 1 2}$ & 575 & 74 & 13 & 662 & 3.6 \\
\hline $\mathbf{1 , 9 1 3}$ & 906 & 179 & 16 & 1,101 & 6.0 \\
\hline $\mathbf{1 , 9 1 4}$ & 730 & 186 & 32 & 948 & 5.2 \\
\hline $\mathbf{1 , 9 1 5}$ & 935 & 219 & 70 & 1,224 & 6.7 \\
\hline $\mathbf{1 , 9 1 6}$ & 963 & 138 & 36 & 1,137 & 6.2 \\
\hline $\mathbf{1 , 9 1 7}$ & 1,254 & 324 & 48 & 1,626 & 8.9 \\
\hline $\mathbf{1 , 9 1 8}$ & 1,230 & 426 & 4 & 1,660 & 9.1 \\
\hline $\mathbf{1 , 9 1 9}$ & 1,991 & 158 & - & 1,349 & 7.4 \\
\hline
\end{tabular}

\begin{tabular}{|c|c|c|c|c|c|}
\hline $\mathbf{1 , 9 2 0}$ & 602 & 79 & - & 681 & 3.7 \\
\hline $\mathbf{1 , 9 2 1}$ & 565 & 79 & - & 644 & 3.5 \\
\hline $\mathbf{1 , 9 2 2}$ & 36 & 5 & - & 41 & 0.2 \\
\hline $\mathbf{1 , 9 2 3}$ & 192 & 8 & - & 200 & 1.1 \\
\hline
\end{tabular}

FUENTE. Morimoto, Amalia. “Los inmigrantes japoneses en el Perú”, TEA-UNA, Lima, 1979, pag. 40.

CUADRO No 4

LIMA: DISTRIBUCIÓN DE LA POBLACIÓN PERUANA Y EXTRANJERA: 1903-1931

\begin{tabular}{|c|c|c|c|c|}
\hline AÑOS & TOTAL & \multirow{2}{*}{ PERUANOS } & \multicolumn{2}{|c|}{ EXTRANJEROS } \\
\cline { 3 - 5 } & & & Absoluta & \% \\
\hline $\mathbf{1 8 7 6}$ & 122,326 & 78,854 & 22,634 & 18.5 \\
\hline $\mathbf{1 9 0 8}$ & 172,927 & 127,583 & 16,531 & 9.6 \\
\hline $\mathbf{1 9 2 0}$ & $223,807^{*}$ & 203,807 & 15,957 & 7.1 \\
\hline $\mathbf{1 9 3 1}$ & $373,875^{*}$ & 348,265 & 24,610 & 6.6 \\
\hline $\mathbf{1 9 4 0}$ & 533,645 & & 28,110 & 5.3 \\
\hline
\end{tabular}

FUENTES. 1857: M.A. Fuentes, Estadística General de Lima, 1858

1876: Censo General de la República, 1876

1908: Censo de la provincia de Lima, 1908

Revista "Tierra Nuestra” UNALM

1920: Censo de Lima y Callao 1920 